\title{
Engineering at the Nanoscale: A Strategy for Developing High-Performance Functional Polymer Nanocomposites ${ }^{\dagger}$
}

\section{Sabu Thomas ${ }^{1, *}$}

1 School of Energy Materials, International and Inter-University Centre for Nanoscience and Nanotechnology \& School of Chemical Sciences, Mahatma Gandhi University, Priyadarshini Hills P. O. Kottayam, Kerala, India -686 560

* Correspondence: sabuthomas@mgu.ac.in;

$\dagger$ Presented at Materials Chemistry and Physics (Materials Chemistry 2020) - International e-Conference

Received: 16.09.2020; Revised: 20.09.2020; Accepted: 24.09.2020; Published: 27.09.2020

\begin{abstract}
The talk will concentrate on various approaches being used to engineer materials at the nanoscale for various applications in future technologies. In particular, the case of clay, carbon nanostructures (e.g., nanotubes, graphene), metal oxides, bionanomaterials (cellulose, starch, and chitin) will be used to highlight the challenges and progress. Several bio-degradable polymer systems will be considered, such as rubbers, thermoplastics, thermosets, and their blends for the fabrication of functional polymer nanocomposites. The interfacial activity of nanomaterials in compatibilism binary polymer blends will also be discussed. Various self-assembled architectures of hybrid nanostructures can be made using relatively simple processes. Some of these structures offer an excellent opportunity to probe novel nanoscale behavior and can impart unusual macroscopic end properties. I will talk about various applications of these materials, taking into account their multifunctional properties. Some of the promising applications of clay, metal oxides, nano cellulose, chitin, carbon nanomaterials, and their hybrids will be reviewed.
\end{abstract}

Keywords: composites; polymers; nano materials.

(C) 2020 by the authors. This article is an open-access article distributed under the terms and conditions of the Creative Commons Attribution (CC BY) license (https://creativecommons.org/licenses/by/4.0/).

\section{Funding}

This research received no external funding.

\section{Acknowledgments}

The author acknowledges the research support provided by various agencies like DST, DBT, UGC, AICTE, DRDO, and CSIR.

\section{Conflicts of Interest}

The authors declare no conflict of interest. 